\title{
Enhancing One Stop Centre in the Malaysian Planning System
}

\author{
Marlyana Azyyati Marzukhi ${ }^{1, *}$, Dasimah Omar ${ }^{1}$, Oliver Ling Hoon Leh ${ }^{1}$, Na $^{\text {'asah Nasrudin }}{ }^{1}$ and Azfarnizam Jaafar ${ }^{2}$ \\ ${ }^{1}$ Faculty of Architecture, Planning and Surveying, Universiti Teknologi MARA, Selangor, Malaysia \\ ${ }^{2}$ Subang Jaya Municipal Council, Subang, Malaysia
}

\begin{abstract}
Malaysia has been experiencing rapid development since its independence in 1957, which has transformed its economic base from agriculture to industry. Rapid urbanisation has itself led to the continued rise of economic growth and the need for obtaining permissions from the relevant authorities to ensure an effective and efficient planning system. This effort is evidenced by the improvement of mechanism delivery system of planning and building plan process, known as One Stop Centre (OSC). The Ministry of Urban Wellbeing, Housing and Local Government initiated OSC on the $13^{\text {th }}$ April 2007 to improve the planning delivery system and procedures at all local planning authorities by coordinating and shortening the approval process. However, relatively little is known about the effectiveness of OSC and the understanding of its roles among the stakeholders in the local authority. Therefore, a questionnaires survey has been conducted to forty-seven (47) respondents and interviews with the public that involved in the process. The respondents have mostly felt that the ineffectiveness of the planning and building plan approval process was due to the incomplete documents submitted to the OSC, lack of knowledge among the Professional Submitting Person (PSP) and the incapability of staffs in handling development applications. Hence, the findings present a synthesis of results for town planners, architects, developers and government agencies to have a better understanding of OSC. Thus, the knowledge serves as a basis for future strategic planning decisions and guidance in the delivery system in Malaysia.
\end{abstract}

\section{Introduction}

In recent decades, the expansion of cities is rapidly happening in the world. By 2030, developing nation's populations will become double in size and the city areas could be tripling [1]. It is also expected that by 2025 the market volume of construction industry could reach $\$ 15$ trillion and is to grow by $70 \%$ or more [2]. Rising population nowadays has caused the increasing demand for municipal authorities to deliver its services. Building authority, particularly in the developed nations are facing difficulty in enforcing standards, laws, or guidelines in order to deliver efficient and comprehensive development due to the shortages in budgets and resources. The federal government of Malaysia understands the need to speed up and standardize the design approval procedures, and they have introduced the One Stop Centre (OSC) framework on April 13, 2007, to help expedite approval of development [3]. It also provides local authorities in Malaysia the standard design approval procedure for new developments application. Therefore, the objectives of this article are to assess the effectiveness of OSC and the understanding of its roles among the stakeholders in the Malaysian planning system.

The success of a development project is crucial to all the stakeholders who primarily are the developer, the landowner, and property buyer. The timely completion of a project that is not only within the budget but also in accordance to specifications and the stakeholder's satisfaction benefits both the project owner (developer) and the property buyer [4]. Every project development will undergo some form of project life cycle (PLC) [5]. Time and procedures in construction permitting is the most significant "regulatory impediment" to doing business. Time taken by authorities especially for the issuance of design approval is uncertain and difficult to predict [6]. Similarly, a case study carried out by Mitropoulos and Howell [7] found that the main reason for the delay in refurbishment projects was the process of getting approval from the local authority. When delay occurred, the overall cost for the project would also be affected. McKim et al. [8] mentioned that one of the factors contributing to cost and schedule overruns is the regulatory requirements. In some cases, the drawings had to be submitted more than once due to the amendment that needed to be incorporated. This is sometimes due to the complexity of requirements set by the respective authorities [8].

Construction regulation matters for public safety. If procedures are too complicated or costly, builders tend to proceed without a permit [9]. By some estimates, 60$80 \%$ of building projects in developing economies are undertaken without the proper permits and approvals [10]. Construction regulation also matters for the health of the building sector and the economy. Based on a study conducted by OECD [11] the construction industry

Corresponding author: marlyana@salam.uitm.edu.my 
accounts on average of $6.5 \%$ of GDP in OECD economies. Proper regulations help to ensure the safety standards that protect the public while making the permitting process efficient, transparent and affordable. Applying for planning and building plans approval as the first step before development begins to ensure that development plans will be reviewed by qualified personnel to limit the risk of construction failures. If the plans do not need the review from anyone, there will be no clear way to make sure that any developments complied with proper standards or laws.

A planning application is a submission of documentation which is prepared by an applicant who is seeking planning permission or consent to build on the land, carry out development works or change the use of premises. The application is typically assessed by the planning department within a town or city council or municipal authority. A valid planning application is required that contain details on the full extent of development or works proposed, the name and address of the applicant, expected impact upon sensitive land uses and other related information. The planning department typically assesses the application within a town, or city council to see if it is compliant with the policies and objectives of the development plan and other material of planning considerations, such as its impact on adjoining land uses. Public participation in the planning process is actively encouraged, with the planning application procedure usually open to public consultation for a set period, which means that members of the public can make a submission or observation in support of or to object any planning application. A decision on the planning application is made once compliance with planning policy, envisaged material planning impacts and the views of public consultees are all assessed, and the proposed development is either granted or refused permission. The plan reviewer is the approval giving the party that generally served the local government [12].

\section{Literature}

The approval-giving party; or called 'permit authority' by some countries; usually is the local authority or local government of the area where the development work or building work is located. They have empowered the rights to control developments, building occupation and the building demolition. They grant the planning approval and related permits that includes construction permit, demolition permit or occupancy permit. They also make the regular checks to ensure the development or building works comply with conditions of permits. The local authority is responsible for ensuring that all application for related construction works follows all the rules and related laws. The records of the relevant construction works shall be accessible to authorized people; the current or the subsequent owners; and the local authority shall be responsible for maintaining the records.

The planning and building plans that are approved by the local authority must be presented before any work may commence on site and the approval can be shown directly on site with the erection of project signboard. This will enable the local authority to cross-check the compliance of a project via the references displayed in the signboard. Usually, the project signboard must reflect the title of the project, the project's reference number, the name of the developer (or owner of the premise), the name of the project consultants and the related contacts person. Furthermore, the growth in construction activities has given rise to the need for more refined statutory controls to ensure systematic and orderly development. The laws, procedures, and guidelines on the land and property development process in Malaysia are quite extensive. Some of the statutes involved are National Land Code 1965 (Act 56), Town and Country Planning Act 1976 (Act 172), The Local Government Act 1976 (Act 171) and the Road, Drainage and Building Act 1974 (Act 133).

However, over the years, the local authorities in Malaysia have been roundly criticized for poor services particularly in planning and development. Due to the importance of services that local authorities provide, they are subjected to a daily barrage of questions and complaints by the public directly in the press and even at the state and federal levels. The procedures available have never been transparent or understood by most of the people. The rule and policies of government change continuously. Unrelenting bureaucracies and vague processes made housing developers complained about approval delays, lack of transparency and other improprieties in the real estate industry [13]. Therefore, to overcome the delay in processing the planning and building plan application, the Ministry of Urban Wellbeing, Housing, and Local Government recommended that a standard, uniform workflow chart shall be conducted simultaneously by all agencies involved. The Ministry proposed that procedures and work processes for the proposed development proposals need to be revamped and adjusted following the provisions of the laws. The application will be implemented simultaneously through the new One Stop Center (OSC) approach, by performing a uniform processing flow chart. For the purpose of improving the delivery system, this proposed approach should be adopted by all local authorities. Therefore, all local authorities should immediately set up an OSC to manage development proposals covering planning permission applications, building plans, land-based plans and landscaping plans from applicants. In this regard, an OSC Committee is established and authorized to consider and decide upon the application for planning permission, building plan and inform planning approvals, simultaneous application of subdivision and change of conditions, and, surrender and re-alienation to land administrator [14].

In order to ensure smooth processing, each development proposal submitted by the consultant on behalf of the developer to the OSC Secretariat shall contain all the complete information and documents following the designated checklist. The OSC Secretariat will register a complete application. Subsequently, the 
secretariat will take immediate action to distribute landrelated applications (change of conditions, subdivision, simultaneous change of conditions and subdivision, surrender and realienation) to land offices, application for planning permission to the Planning Department of local authority while building plan application to the Building Department of the local authority. The Secretariat will also distribute the applications to the external related technical department for comments and views. The question of what is mean by performance in the public service context, and how can it best be measured always arise due to lack of services and human resources.

Public contributions to planning processes tend to be near universally accepted in the literature. In this twentyfirst century, it is essential to emphasize the convergence of interactions between the authority and the public, affecting the rationale of the authority's action [15]. These interactions highlight a significant form of participation that emphasizes the dynamic practices of the local authority, where the rights of all concerned parties are generally acknowledged [16]. In this sense, the dynamic networks between actors are demonstrated in an arena that is open to discussion and values differing opinions in the planning process [17]. Local authority performance can be represented based on rational organizational effectiveness and responsiveness. On the level of individual citizens, responsiveness means the helpful and prompt action in the offices of the local government. If the public feel satisfied, the local authority has achieved a reasonable level of responsiveness and efficiency. More substantive responsiveness can be captured through the correspondence between local government policy objectives and citizens' wants and needs. If the local government can address local people's demands, it shows responsiveness. It is to be examined, however, what qualifies for representing public concerns in the eyes of decision-makers and administrative officials: the opinion of elected representatives, the public opinion (gauged through local polls, for instance), and the opinion of the noisiest or the best organized or otherwise resourceful groups in the local community. Finally, responsiveness also implies the implementation of policies in a way that meets people's expectations. The level of satisfaction with the services and programs of local government shows this kind of responsiveness.

It is difficult to assess how well a local authority is performing because there is no owner with an equity stake in the local authority demanding or requiring measurement. There is no bottom-line of profitability or easily quantifiable outcomes that can be used as a benchmark. As a government agency, the local authority is not focusing on profitability but rather on providing services for the well-being of its community. In other words, even the public communities may assess the performance of their local authority by looking at whether they have been served to a satisfactory level but still insufficient. The public is not so much concerned about whether the local authority is having enough resource or not since they expect that resources would come from the government. The public also does not consider whether local authorities are develop oriented rather than service oriented which has limitations in certain conditions. However, local authorities are accountable for the performance of their organizations. The stakeholders who are interested to know their performance include the Members of Parliament, the local authority's council members, the community or the taxpayers the local authorities are serving, the public at large as well as the mass media. Because of this, the community is becoming more vocal in voicing their rights over the services provided by their local authorities. They are also demanding more transparent and higher accountability for the way their local authority make decisions particularly in the planning and development of their area. Although OSC is not directly involved with the public in the decision-making the process itself - from submission to approval - that involve many stakeholders such as planners, architects, and engineers are vital to enhancing OSC. Furthermore, the limits of participation have created significant challenges for the Malaysian planning system. Therefore, this article is important to assess the effectiveness of OSC and the understanding of its roles among the stakeholders in the Malaysian planning system.

\section{Case Study and Methods}

The Subang Jaya Municipal Council (MPSJ) is one of the local authorities located within the Klang Valley Region, Malaysia is selected as a case study. It was established in accordance with the Local Government Act 1976 (Act 171) under Section 4. For questionnaires survey, 47 respondents were selected which includes the public who submitted the plans, officers in charge of development control from Building Department, Town Planning Department, Engineering Department and OSC Department in MPSJ. Three (3) interviews were conducted with professional submitting person (PSP) to obtain their opinions and feedback on the development application procedure at the authority. Interviews are only conducted with the PSP because according to the law, the regulation and all development procedures, only the PSP can apply for new developments and the project owner as their proxy appoints them. They were being explained of the nature of the research and confidentiality. The interview sessions were conducted between October and November 2017.

\section{Analysis and Findings}

\subsection{Questionnaires}

\subsubsection{Roles of OSC}

Most of the respondents $(46.81 \%, 22$ respondents) were unsure whether the public fully understands the current procedures of OSC, while some of them (31.91\%, 15 respondents) believed that the public does not understand at all. Only a few $(21.28 \%, 10$ respondents $)$ thought the 
public follow the procedures of OSC. The respondents, however, agreed that technical departments within MPSJ understand the processes $(42.55 \%, 20$ respondents) while only some were unsure $(34.04 \%, 16$ respondents). Just a few believed the internal technical departments do not understand the procedures $(23.41 \%, 11$ respondents). The respondents felt that workforce in OSC department of MPSJ is adequate now $(44.68 \%, 21$ respondents) but they believed more manpower is needed in the future $(57.45 \%$, 27 respondents). Most of the respondents believed that officers of OSC department have the skills $(63.83 \%, 30$ respondents) and the knowledge (65.96\%, 31 respondents) required to manage planning and building plan applications and procedures. However, the respondents believed that OSC officers should possess the ability to instruct PSP because 11 respondents $(23.40 \%)$ does not agree that OSC officers capable of doing that while 16 respondents $(34.04 \%)$ unsure whether OSC officers were able to do that. Only 20 respondents $(42.56 \%)$ believed OSC officers capable of instructing the PSP in following the procedure.

\subsubsection{Planning and building plans approval}

Some of the respondents agreed that the officers in MPSJ were continually being reshuffled $(29.79 \%, 14$ respondent) while only 9 respondents $(19.15 \%)$ disagreed. Most of the respondents $(51.06 \%, 24$ respondents) unsure whether the reshuffling was constantly done. Most of the respondents $(51.06 \%, 24$ respondents) agreed that most PSP have a lack of knowledge about their job. However, most of the respondents felt that MPSJ has a strict planning and building plan procedures (44.68\%, 21 respondents) and the procedures involved too many officers $(65.96 \%, 31$ respondents). The application letters sent to MPSJ were arranged in a hierarchical order (74.47\%, 35 respondents) and the officers in charge usually received the letters on a different day from the day it was received, and this promotes delay. The PSP; due to lack of knowledge; have often presented MPSJ with incomplete documents during discussion and preconsultation $(59.57 \%, 28$ respondents) thus causing further delay in the process. However, MPSJ felt that all related parties fully understood the requirements of planning and building plans $(51.06 \%, 24$ respondents). 33 respondents $(70.21 \%)$ have stated that they would like to have an online notification system adopted by MPSJ as this will combat the delay caused by post mails.

\subsubsection{Procedure and timeframe of OSC}

From the survey, it was found that the OSC department did inform all the stakeholders about its procedure and the duration related to the procedures $(65.96 \%, 31$ respondents). The survey has also shown that the OSC has served purposes that were initially outlined in the year 2007 (63.83\%, 30 respondents) particularly in simplifying land related procedures (55.32\%, 26 respondents). Most of the respondents agreed that time needed for first checking and review is 14 days $(78.72 \%$, 37 respondents) and all applications will be brought to
OSC Committee meeting within 30 days (82.98\%, 39 respondents). After the meeting, the respondents believed that the applicant might return the amended plans within 60 days from the date of release of OSC meeting's minutes $(57.45 \%, 27$ respondents). The respondent also felt that most PSP has been able to give a speedy return of the amended plan on time (55.32\%, 26 respondents).

\subsection{Interview}

\subsubsection{Roles of OSC}

All PSP interviewed were not totally well-versed with the timeframe involved with OSC procedures. This may be due to the lack of skills of the OSC department to inform the PSP and lack of knowledge to handle the planning and building plans applications. These reasons were agreed by all the PSP. All the PSP also felt that the front desk people of OSC department were lacked experiences. Even the current setting in OSC department failed to help them understand about development requirements; the setting is only for submission and document checking. Two out of three PSP believed OSC Department has manpower shortage. All PSP agreed that only the department within the MPSJ understand the procedure (the internal technical department) while the external technical departments do not understand the overall procedure. All PSP agreed that the planning and building plans procedure were complicated and difficult particularly on the earlier stage of submission and followup stage after the amendments have been done.

\subsubsection{Planning and building plans approval}

Overall, all PSP believed some MPSJ officers were inefficient, competent and had lack of experience. All PSP felt that the building plan applications in MPSJ have reached the level of expectation among the PSP and they were satisfied with the performance of the MPSJ procedures. However, they said the OSC department still need to have a more defined role among its officers because all other internal technical departments have shown that they have. A good practice of information storage and filing; complete with a handing-over list and PDF-supported softcopy of information; will complement the practice of staff or officers' reshuffling. Mentoring and tutoring should also be done to ensure that the successor officer can carry out the previous workload and at the same time bear the latest workload.

There were three (3) main reasons that resulted in the delayed of OSC procedure. The reasons generally due to the slow action and negligent of PSP, uncompleted documents resubmitted by PSP and the extra unwrittenreview by the local authority. The PSP normally received the decision letter from the OSC Committee Meeting in one to two weeks, one to two month and sometimes PSP decided not to wait and follow up directly with the officers in charge, and this will take extra two (2) days. There is also a situation where the postal mail did not reach the PSP at all. All three PSP believed that an online 
system needs to be used by MPSJ to help PSP get the review as soon as possible; if possible, as soon as the letter is endorsed and confirmed by the Council President. The notification system of MPSJ is also to be blamed as it caused delay especially when the results of the OSC Committee Meeting being distributed to PSP. Another cause of the delay is the checklist used by departments in MPSJ. The PSP is entirely responsible when delays occur because their actions determine the direction of an application.

All PSP agreed that currently, all development requirements in MPSJ were at a very satisfactory level regarding legislation. Development requirements were also explicitly stated by MPSJ. All PSP believed the OSC department does not have the skills to make preconsultation and fee calculations. Only documents were reviewed at the OSC department while fee calculation and pre-consultation of plans were carried out according to the department involved; for example, building plan in the Building Department and site layout plan in the Town Planning Department. Usually, the OSC department will instruct the PSP to meet officials of various departments (excluding OSC department) that involved with the new development application.

\subsubsection{Procedure and timeframe of OSC}

Two out of three PSP believed no application for building plan permits could be approved within four (4) months in MPSJ. One PSP thought that it is possible; $50 \%$ of the time; for application to be approved within four (4) months. What is essential is for the PSP to have a very comprehensive pre-consultation in the initial stage. In order to complete the follow-up stage of OSC procedure, a total of one (1) week to a month is needed to make corrections and amendments before complying with the review. Two PSP believed it is possible for MPSJ to produce the decision 30 days after the submission of building permit application. This can be achieved by MPSJ if pre-consultation is made before the building permit application is submitted at the counter. This is also possible if there is a proper notification system used by MPSJ. Pre-consultation is deemed to be very important and essential to have a good start, and all the three PSP agreed on this. But, no in-depth pre-consultation is provided by OSC Department as the department is only a place where the document being submitted and distributed (like courier service) and OSC department shall forward inquiry regarding the requirements to the respective technical departments.

All PSP believed the OSC Department does not do everything possible to disseminate information regarding the procedures and time periods in planning and building plan applications. No positive changes were made, and the OSC department's work procedures seem to be more complicated and more time-consuming. Two out of three PSP felt that they have no problem to access information related to OSC procedures be it at the counter or online. But, according to both, OSC department personnel were still incapable of providing information related to planning and building plans requirements along with related timeframe of MPSJ. They just merely unqualified and yet to master all the relevant development requirements.

\section{Conclusion}

One of the issues in planning and building plan application is the delays. The OSC procedure itself causes the delays because it involved too many officers, and the Professional Submitting Person (PSP) presented MPSJ with inadequate documents that end up dragging the application further into the delay. The delay is also caused by the lack of workforce and expertise at the front counter in OSC department even though the current number of officers at OSC department is capable in terms of skills and knowledge. Due to this, the OSC counter is incapable of conducting most technical requirements like fee calculation, pre-consultation and technical discussions. Generally, even the MPSJ officers are lack of experience, inefficient and competent. Other causes of delay are the slow-acting and negligent among the PSP, the MPSJ notification system and the checklist used by departments in MPSJ.

The PSP; or the consultant; is the key to every successful application. If they do not have the fluency towards the development guidelines and regulations one shall expect instant failure. To avoid that every PSP must be well-prepared towards any submission of planning and building plans application. There is always a need for constant reform of development regulations and the use of information technology to ensure better physical development control and enforcement. As a start, every local authority shall improve their server size (for data storage) as soon as possible. Improved server size will enable the local authority to explore new ways to give better services to the public. One example is the mailing system. With online mailing system, any PSP might able to receive plan reviews with a click of a button (or from a simple SMS).

Furthermore, pre-consultation at the OSC is crucial as stated by the World Bank in its publications [12]. The OSC department particularly the front desk officers must be able to answer questions or at least try to assist the applicants. Perhaps, the OSC department must improve their roles by deploying capable and knowledgeable officers. OSC must be the centre for excellence (for development approving) where both the department and its personnel must be highly competent and well-versed in all related development matters. To be able to do that, all the OSC officers must involve more with the development matters as this will surely promote competency and transparency not just within the OSC department but also in the local authority itself.

The authors would like to thank the National Institute of Valuation (INSPEN) for supporting the study through NAPREC Grant (100-IRMI/GOV16/6/2(011/2018), the Universiti Teknologi MARA (UiTM), all the government 
departments, organisations and individuals who have contributed to this study.

\section{References}

1. United Nations 2016. The World Cities in 2016 Data Booklet. Retrieved from www.un.org/en/.../desa/population/.../the_worlds_cit ies_in 2016 data booklet.pdf.

2. Global Construction 2025 Report 2013. Retrieved from https://assets.publishing.service.gov.uk.

3. PEMUDAH 2010. Seminar on the First Steps of Successful Reform in Doing Business, Taipei, Chinese Taipei, 5- 6 October 2010

4. L.D. Nguyen, S.O. Ogunlana, D.T.X. Lan. A study on project success factors in large construction projects in Vietnam. Engineering, Construction and Architectural Management, 11 404-13 (2004)

5. Kerzner H. Project management: A system approach to planning, scheduling, and controlling (New York, Van Nostrand, 2009)

6. Kincaid D. Adapting buildings for changing uses, guidelines for change of use refurbishment (London: Spon Press, 2003)

7. Mitropoulos, Howell. Renovation projects: Design process problems and improvement mechanisms. Journal of Management in Engineering, 18 179-85 (2002)

8. R. McKim, H. Tarek, M. Attalla. Project Performance Control in Reconstruction Project. Journal of Construction Engineering and Management, 126 137-41 (2000)
9. Moullier T. Reforming Building Permits: Why is It Important and What Can IFC Really Do? (Washington, DC: International Finance Corporation, 2009)

10. De Soto H. The Mystery of Capital: Why Capitalism Triumphs in the West and Fails Everywhere Else (New York: Basic Books, 2000)

11. OECD. OECD Guidelines for Multinational Enterprises (France: OECD Publishing, 2010)

12. The World Bank 2018 Doing Business 2018. Reforming to Create Jobs. A World Bank Group Flagship Report (Washington)

13. Dzulkifli W. M. Panduan dan Prosedur Asas Cadangan Pembangunan Projek Perumahan (Pulau Pinang: Universiti Sains Malaysia, 2009)

14. Ministry of Urban Wellbeing, Housing and Local Government, Malaysia. Upgrading of the Procedure on the Delivery System and Development Plan Process and the Implementation of the One Stop Centre. (Malaysia: Kuala Lumpur, 2007)

15. N. Bailey. Understanding community empowerment in urban regeneration and planning in England: putting policy and practice in context. Planning, Practice \& Research, 25 317-32 (2010)

16. S. Brownill, G. Parker. Why bother with good works? The relevance of public participation(s) in planning in a post-collaborative era. Planning, Practice \& Research, 25 275-282 (2010)

17. Healey P. Collaborative Planning: Shaping Places in Fragmented Societies (New York: Palgrave Macmillan, 2006) 